\title{
Reducing Paediatric Outpatient Waitlists-A Proposed Allied Health Multidisciplinary Approach
}

\author{
Hsien-Jin Teoh', Millie Darvell² \\ ${ }^{1}$ Redcliffe Hospital, Metro North Hospital and Health Service, Queensland, Australia \\ ${ }^{2}$ Private Practice, Queensland, Australia \\ Email: hsien-jin.teoh@health.qld.gov.au
}

How to cite this paper: Teoh, H.-J. and Darvell, M. (2021) Reducing Paediatric Outpatient Waitlists-A Proposed Allied Health Multidisciplinary Approach. Open Journal of Preventive Medicine, 11, 63-70. https://doi.org/10.4236/ojpm.2021.112006

Received: January 7, 2021

Accepted: February 17, 2021

Published: February 20, 2021

Copyright () 2021 by author(s) and Scientific Research Publishing Inc. This work is licensed under the Creative Commons Attribution International License (CC BY 4.0).

http://creativecommons.org/licenses/by/4.0/

\section{(c) (i) Open Access}

\begin{abstract}
Extremely long Australian paediatric outpatient waiting lists have resulted in large numbers of children waiting to see a paediatrician. Analyses of the patient referrals suggest that a large proportion of children may benefit from allied health input, in addition to being seen by the paediatrician. This paper provides an organisational strategy that involves streamlining Allied Health clinical services in an effort to assist with bringing down a Paediatric Out-patient waitlist. The paper describes principles to guide the formation of a Paediatric Allied Health Multi-Disciplinary team that proposes assessment and brief interventions. The service would focus on supporting the paediatricians through the use of structured procedures, telephone intakes, multidisciplinary triage, shared and standardised assessments, collaborative formulations and reports, brief interventions, clinical-community linkages, and allied health student support. A variety of additional important organisational principles are proposed to facilitate patient flow from the perspective of streamlining administrative processes, having adequate administrative support, shared responsibilities, teamwork, flexibility, carrying out intake assessments, determining which referrals were appropriate for allied health, and working closely with medical staff.
\end{abstract}

\section{Keywords}

Paediatric, Out-Patient, Allied Health, Multi-Disciplinary, Waiting Lists

\section{Introduction}

Growing demand for paediatric services has witnessed growing hospital out-patient waiting lists becoming a common occurrence across some Australian hospitals, 
where some children have to wait for a diagnosis for up to 23 months [1] [2] [3]. In some facilities, as many as 200 patients would have been waiting for an extended period of time, and in others as many as $61 \%$ on the waitlist had waited more than 365 days [2] [4]. As children are a patient cohort who are constantly developing physically, emotionally and socially, a problem that has been identified, would usually continue to deteriorate, and may have morphed into a more complex disorder by the time they are attended to in the hospital. Furthermore, the child's behavioural and emotional difficulties impact their immediate family, and that of their educational environment. Thus, when left untreated stress and strains, feelings within the home and school environment are increased. With this in mind, strategies to help reduce the Paediatric waitlist, and also the amount of time children are waiting to see a health care professional, and are constant issues that health care planners grapple with.

\section{Approach to Analyzing the Problem}

Studies on the types of patients attending paediatric out-patient clinics suggest that many patients may have benefitted from allied health input prior to, or whilst, seeing the paediatricians [5]. The patient types included regular presentations of Attention Deficit Hyperactivity Disorder, learning disability, autism, self-harm, anxiety, mood disorder, behavioural problems and speech delay. Specifically, these allied health professionals would include psychologists, speech pathologists and occupational therapists. Complex cases may require multidisciplinary, multi-agency and multi-modal approaches to assess and diagnose. Such approaches have been recommended for Attention Deficit and Hyperactivity Disorder $A D H D$ [6], Autism Spectrum Disorder ( $A S D$ ) [7], and developmental delay [8].

In addition to understanding the paediatric patient cohort, anecdotal assumptions and research on general factors that lead to out-patient waiting lists that have spiralled out of control suggest concerns in the areas of team system, communication, framework and efficiency, misalignment of clinical resources, unclear staff roles, multi-professional autonomy and increasing number of patients referred into the public health system [4] [9] [10]. Whilst the increasing number of patients may be something that public health care facilities may not be able to do much about, there may be more that may be done in relation to the manner in which healthcare teams are organised, promoting clearer communication, and clarification of the manner in which team clinicians contribute to cases.

Based in understanding the type of cases that often appear in paediatric clinics, and some of the general factors that may contribute to increasing out-patient waitlists, this paper proposes a series of principles to guide a Paediatric Allied Health Model-of-Care that may be used to support the paediatrician's efforts by streamlining efforts to reduce hospital wait lists. The paper's focus is on explaining in some detail what each principle strategy is, as identified in the re- 
search literature. Through this focus, the reader may obtain some guidance with regards to shaping an existing service.

\section{Management Approaches to Addressing the Problem}

A review of the literature suggested the following operational principles:

- Principle 1: Structured intake assessments

- Principle 2: Multidisciplinary triage and assessments

- Principle 3: Single shared multidisciplinary reports

- Principle 4: Brief interventions and referrals to community facilities

- Principle 5: Student interns facilitated clinics

The proposed Paediatric Allied Health Model-of-Care embodies work practices which would help to reinforce managerial and reporting structures, encourage collaboration and cohesion, enhance communication, and facilitate the flow of patient care. The team would consist of psychologists, speech pathologists, occupational therapists and social workers, all of whom would be involved in intake assessments and contribute towards multi-disciplinary assessments and brief interventions. The following are descriptions of the operational principles by which they would operate.

\section{Principle 1: Structured Intake Assessments}

Referrals received by paediatricians from local General Practitioners may vary in terms of the quality of information provided. Thus, it is necessary to clarify with the parents about their child's underlying issues and history of the presenting problems via a semi-structured interview. Semi-structured questionnaires have been recognised as an integral mechanism for the execution of collaborative work [11], and associated with improved clinical outcomes [12]. A questionnaire would include questions on developmental, behavioural and emotional issues, and that could be administered by any Allied Health clinician.

\section{Principle 2: Multidisciplinary Triage and Assessments}

The interview information would be reported back to a team, which provides team clinicians with a chance to review cases and reach a consensus on the type of allied health input required [13], prevent clinical care from becoming fragmented by establishing a case manager [14], and providing for more thorough decision making [15]. Standardised and empirically-validated instruments may be part of the assessments used to assess behaviour, development, cognitive ability, language and sensory issues.

\section{Principle 3: Single Shared Multidisciplinary Reports}

Upon conclusion of the assessments, a shared multidisciplinary report would be compiled for each patient using standardised formats and language which enables various care approaches to be communicated in a unified manner [16]. Each clinician provides assessment results and recommendations for care. A shared secure online system may be used as a single, integrated record keeping system for report writing, which encourages multidisciplinary team work via enhancing information sharing and communication [17]. The Case Manager 
would coordinate the meetings to write a joint formulation of the patient's presenting problems. Patients' parents are provided with verbal and written feedback, and two copies of the report. Reports would subsequently be sent to the referring General Practitioner and Paediatrician.

Principle 4: Brief Interventions and Referrals to Community Services

Given that the Paediatric Allied Health Multi-Disciplinary team would be located within a general hospital setting, long term ongoing care or therapy may not always be available. Thus, one of the primary aims of the team would require familiarity with local community services, seek out, and facilitate referrals of patients to appropriate longer-term supports within the community. Where a brief intervention might be of benefit to the patient, the team may offer brief interventions. This decision would be contingent upon the urgency of the patient's needs and the availability of other potentially more appropriate services. Examples of common brief interventions that may be utilised include components of parenting programs, child behaviour management, anger management, social skills training, attention focusing strategies, handwriting skills, visual perceptual tasks, sensory integration, speech, language and literacy therapies, and cognitive behavioural interventions to reduce anxiety.

\section{Principle 5: Student Intern Facilitated Clinics}

Utilisation of student interns within a Paediatric Allied Health Multi-Disciplinary service would help to facilitate a larger number of patients being seen through the service. Student-supported clinics have become increasingly popular in recent years due to the growing need within Australia to increase patient capacity and expand student placement opportunities [18]. Traditionally, this approach has involved medical students [19], although, more recently it has expanded to involve allied health disciplines [20]. Some studies suggest that student-supported clinics have significant consumer health benefit as they are considered at least equivalent in their delivery of effective treatment [21]. It is important to note, however, that such clinics are not necessarily designed to provide continuous, long-term care [22], rendering alternative pathways via community partnerships essential [23]. As part of the Paediatric Allied Health Multi-Disciplinary internship, it is recommended that in-house orientations and discipline-specific training programs are offered to students' to build on their university skills and familiarise them with the allied health team, before the internship commences.

\subsection{Challenges}

In setting up a Paediatric Allied Health Multi-Disciplinary service, dealing with complex, multi-layered patient care requirements would be a constant challenge and thus a collaborative and well-coordinated approach would be required.

There would be both strengths and limitations with regards to this Paediatric Allied Health Multi-Disciplinary Model of Care. The strengths included saving the paediatricians time where requiring more detailed assessment results to make informed diagnostic decisions are concerned. As a result, the recommen- 
dations for therapy made by both allied health professionals and the paediatricians would be comprehensive. Given that structured intakes, standardised assessments, and subsequently standardised multidisciplinary report templates are used, the capacity for attending to larger numbers of patients attended to in a streamlined manner would be possible. No model of care is without its limitations, and as a multidisciplinary approach may result in over-diagnosis, the Paediatric Allied Health Multi-Disciplinary team would have to limit assessments to those which address the main Paediatrician or General Practitioner referral question or request. As the specialised nature of the work involves complex multidisciplinary assessments, the manner of communicating findings to the stakeholders involves a large amount of report writing, which may place a heavy burden on clinician time. Thus, there was a constant need to source less time consuming ways of scoring assessments and write reports.

In addition to the operational principles provided, several other logistical considerations may enable more efficient functioning of the paediatric allied health team. These are detailed in the following sections.

\subsection{Team Leadership}

Teamwork, open communication and a shared set of values would facilitate the manner in which the team carries out its daily activities. The challenge would involve moulding experienced clinicians into a collaborative working unit that would work efficiently to ensure a large number of patients continue to be attended to. The multidisciplinary team would be led by a team leader whose role provides effective management which is an integral part of collaborative work. Ovretveit [24] suggested that a team manager should be actively involved in ensuring that practice standards are met, establishing and reinforcing procedures and priorities regarding caseloads, referrals and other clinical matters, and providing support to, and enhancing the development of, staff. The Paediatric Allied Health Multi-Disciplinary Team Leader would have to take responsibility for reinforcing operational policies, training and nurturing staff, and coordinating assessments and interventions, as well as assigning each new referral a case manager.

\subsection{Communication}

Without a well-coordinated and collaborative approach, patient care may become fragmented, healthcare may be under or over-utilised, and patients may become "lost" in the system [25]. To overcome these issues, a number of Paediatric Allied Health Multi-Disciplinary guidelines would have to be established to reinforce managerial and reporting structures that encourage collaboration and cohesion, enhanced communication, and ensured clear roles within the team. In addition to these guidelines, the weekly multidisciplinary meeting, that all clinicians would be required to attend to, help to reduce inadequate communication, poor transitioning of care, insufficient record keeping, lack of administrative 
support, and poor coordination [25] [26].

When catering to the needs of students within the team, there are several recommendations. Firstly, students need to have clinical supervisors who are trained and have the appropriate clinical and supervisory qualifications. The manner in which interns are integrated into the team would need to be facilitated via pre-internship briefings and active participation in meetings, both of which facilitate team communication, a sense of belonging and an attitude of respect. Simply participating as a member of the team and being supervised would not be enough to facilitate student learning of practical skills, and there needs to be a set of resources available that addresses assessments, diagnostic and treatment issues. Supervision also needs to be carried out in a mixture of individual and group modes to ensure that student's individual training needs are considered and that an opportunity exists for broader learning through the shared discussion of cases.

\section{Conclusion}

Principles guiding the formation of a Paediatric Allied Health Multi-Disciplinary model-of-care are proposed to help reduce the paediatric outpatient waiting list. Gradual reduction of the waitlist could begin with an audit of the types of patients presenting to the clinics and considering the types of clinicians best suited to attend to these needs. Following this, the operational processes that contribute to the workability of this model would include structured phone intakes, multidisciplinary triage, assessments, formulations and reports, structured procedures for reports, and intern supported clinics. Setting up teams across health care services would need to be mindful of the current type of case load and also local administrative requirements in order to decide on the type and proportion of allied health disciplines required.

\section{Acknowledgements}

Some aspects of the literature review for this paper have been funded by a grant from the Allied Health Professions Office, Queensland Health, Australia (Grant Ref: AH001082).

\section{Conflicts of Interest}

The authors declare no conflicts of interest regarding the publication of this paper.

\section{References}

[1] Dalzell, S. (2020) Children's Access to Disability Funding Depending on Where They Live Dubbed "Developmental Apartheid". ABC Political.

https://www.abc.net.au/news/2020-02-13/childrens-access-to-disability-funding-de pends-on-their-suburbs/11917466

[2] Caboolture Hospital (2014) Expanded Children's Services Bring Better Care Ca- 
boolture and Kilcoy Hospitals Newsletter.

http://qheps.health.qld.gov.au/cabkilcoy/newsletter/cknewsqoct14s1.pdf

[3] Care Opinion, A. (2017) "Frustrated Family-Referrals and Wait Lists-How to Access Help Quickly” Care Opinion Australia.

https://www.careopinion.org.au/64390

[4] Lawrence, S. and Crombie, J. (2018) When's It My Turn? The Maitland Hospital Paediatric Ambulatory Care Service. Paper Presented at the Centre for Healthcare Redesign Graduation, The Maitland Hospital, NSW, Australia. https://aci.health.nsw.gov.au/ie/projects/whens-it-my-turn

[5] Hiscock, H., Roberts, G., Efron, D., Sewell, J.R., Bryson, H.E., Price, A.M., Wake, M.A., et al. (2011) Children Attending Paediatricians Study: A National Prospective Audit of Outpatient Practice from the Australian Paediatric Research Network. Medical Journal of Australia, 194, 392-397. https://doi.org/10.5694/j.1326-5377.2011.tb03028.x

[6] National Collaborating Centre for Mental Health (2009) Diagnosis and Management of Attention Deficit Hyperactivity Disorder in Children, Young People and Adults. National Clinical Practice Guidelines. Great Britain.

[7] National Autistic Society (2003) National Autism Plan for Children. Author, London.

[8] Royal Australasian College of Physicians (2013) Position Statement: Early Interventions for Children with Developmental Disabilities.

https://www.racp.edu.au/docs/default-source/advocacy-library/early-intervention-f or-children-with-developmental-disabilities.pdf

[9] Naiker, U., FitzGerald, G., Dulhunty, J.M. and Rosemann, M. (2019) Factors Affecting the Performance of Public Out-Patient Services. Australian Health Review, 43, 294-301. https://doi.org/10.1071/AH17285

[10] Johannessen, K.A. and Alexandersen, N. (2018) Improving Accessibility for Outpatients in Specialist Clinics: Reducing Long Waiting Times and Waiting Lists with a Simple Analytic Approach. BMC Health Services Research, 18, 827. https://doi.org/10.1186/s12913-018-3635-3

[11] World Health Organization (2010) Framework for Action on Interprofessional Education and Collaborative Practice. Health Professions Networks Nursing and Midwifery Human Resources for Health. Author, Geneva. http://www.who.int/hrh/resources/framework_action/en

[12] Gandolfi, M., Smania, N., Bisoffi, G., Squaquara, T., Zuccher, P. and Mazzucco, S. (2014) Improving Post-Stroke Dysphagia Outcomes through a Standardized and Multidisciplinary Protocol: An Exploratory Cohort Study. Dysphagia, 29, 704-712. https://doi.org/10.1007/s00455-014-9565-2

[13] Kane, B. and Luz, S. (2011) Information Sharing at Multidisciplinary Medical Team Meetings. Group Decision and Negotiation, 20, 437-464.

https://doi.org/10.1007/s10726-009-9175-9

[14] Burns, T. (2004) Community Mental Health Teams: A Guide to Current Practices. Oxford University Press, Oxford. https://doi.org/10.1383/psyt.3.9.11.50258

[15] Christensen, C. and Abbott, A.S. (2000) Team Medical Decision Making. Cambridge University Press, New York.

[16] Hannigan, B. (1999) Joint Working in Community Mental Health: Prospects and Challenges. Health and Social Care in the Community, 7, 25-31.

https://doi.org/10.1046/j.1365-2524.1999.00160.x 
[17] Onyett, S., Heppleston, T. and Bushnell, D. (1994) The Organisation and Operation of Community Mental Health Teams in England. Sainsbury Centre for Mental Health and Research and Development for Psychiatry (RDP), London. http://www.opengrey.eu/item/display/10068/459201

[18] Peninsula Health (2012) Increasing Capacity through Student Led Clinics. Final Project Report.

http://www.peninsulahealth.org.au/wp-content/uploads/Peninsula-Health-AnnualReport-2012-PDF.pdf

[19] Moskowitz, D., Glasco, J., Johnson, B. and Wang, G. (2006) Students in the Community: An Interprofessional Student-Run Free Clinic. Journal of Interproffessional Care, 20, 254-259. https://doi.org/10.1080/13561820600721091

[20] Holmqvist, M., Courtney, C., Meili, R. and Dick, A. (2012) Student-Run Clinics: Opportunities for Interprofessional Education and Increasing Social Accountability. Journal of Research in Interprofessional Practice and Education, 2, 264-277.

[21] Liberman, K.M., Meah, Y.S., Chow, A., Tornheim, J., Rolon, O. and Thomas, D.C. (2011) Quality of Mental Health Care at a Student-Run Clinic: Care for the Uninsured Exceeds That of Publicly and Privately Insured Populations. Journal of Community Health, 36, 733-740. https://doi.org/10.1007/s10900-011-9367-5

[22] Keis, R.M., DeGeus, L.G., Cashman, S. and Savageau, J. (2004) Characteristics of Patients at Three Free Clinics. Journal of Health Care Poor and Undeserved, 15, 603-617. https://doi.org/10.1353/hpu.2004.0062

[23] Buchanan, D. and Witlen, R. (2006) Balancing Service and Education: Ethical Management of Student-Run Clinics. Journal of Health Care for the Poor and Underserved, 17, 477-485. https://doi.org/10.1353/hpu.2006.0101

[24] Ovretveit, J. (1997) Planning and Managing Teams. Health and Social Care in the Community, 5, 269-283. https://doi.org/10.1111/j.1365-2524.1997.tb00123.x

[25] Walsh, J., Harrison, J.D., Young, J.M., Butow, P.N., Solomon, M.J. and Masya, L. (2010) What Are the Current Barriers to Effective Cancer Care Coordination? A Qualitative Study. BMC Health Service Research, 10, 132.

https://doi.org/10.1186/1472-6963-10-132

[26] Hong, N.J., Wright, F.C., Gagliardi, A.R., Brown, P. and Dobrow, M.J. (2009) Multidisciplinary Cancer Conferences: Exploring the Attitudes of Cancer Care Providers and Administrators. Journal of Interprofessional Care, 23, 599-610. https://doi.org/10.3109/13561820902921829 